\title{
Stereoselective Synthesis of Unnatural Spiroisoxazolinoproline-Based Amino Acids and Derivatives
}

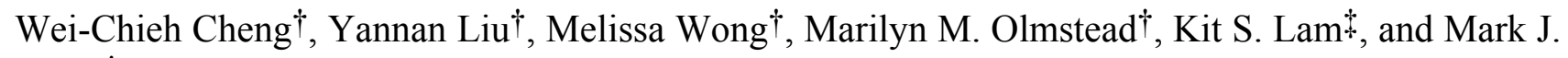
Kurth $^{\dagger *}$

†Department of Chemistry, University of California, One Shields Avenue, Davis, CA 95616-5295

\#Division of Hematology and Oncology, Department of Internal Medicine, UC Davis Cancer Center, University of California, Davis, 4501 X Street, Sacramento, California, 95817

Supporting Information Available:

Copies of ${ }^{1} \mathrm{H}$ NMR and ${ }^{13} \mathrm{C}$ NMR for compound $5,9 \mathbf{a}$, and $9 \mathbf{b}$ and X-ray structures for $9 \mathbf{b}, \mathbf{1 3 a}$, and 15 (9 pages).
${ }^{1} \mathrm{H}-\mathrm{NMR}$
${ }^{13} \mathrm{C}-\mathrm{NMR}$
X-ray

5.

SI 2

SI 3

9a.

SI 4

SI 5

9b

SI 6

SI 7

SI 8

13a.

SI 9

15. 


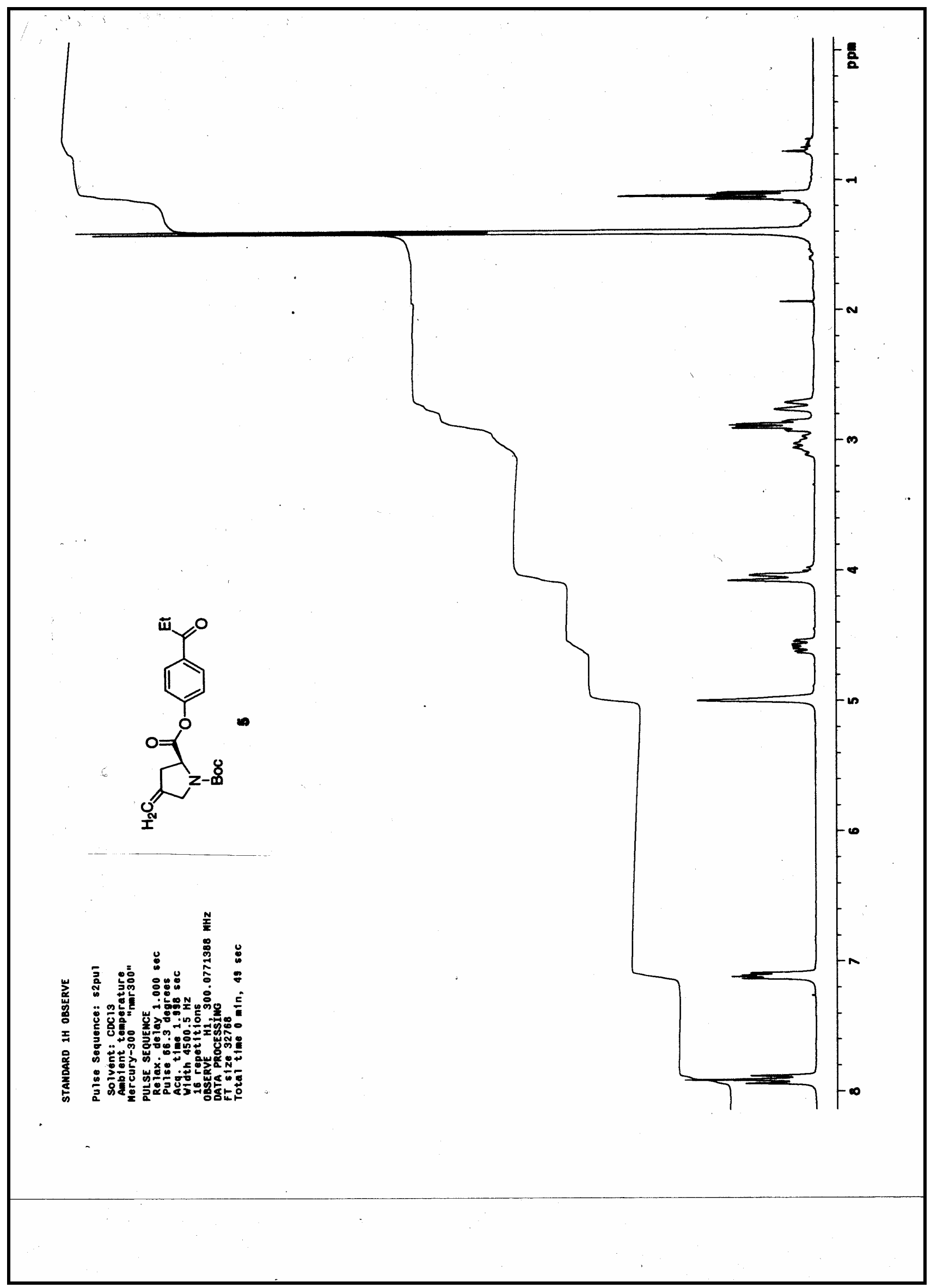




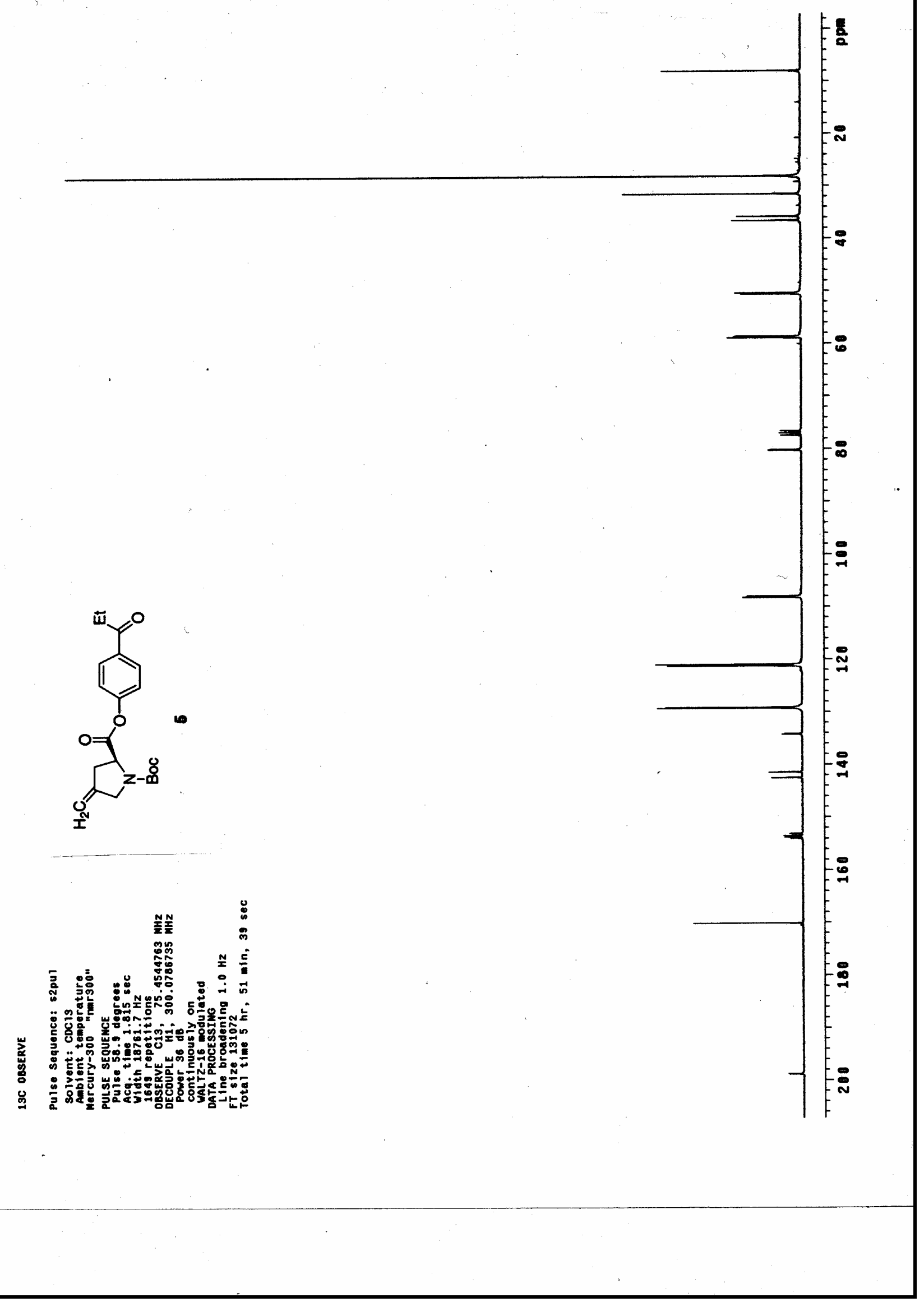




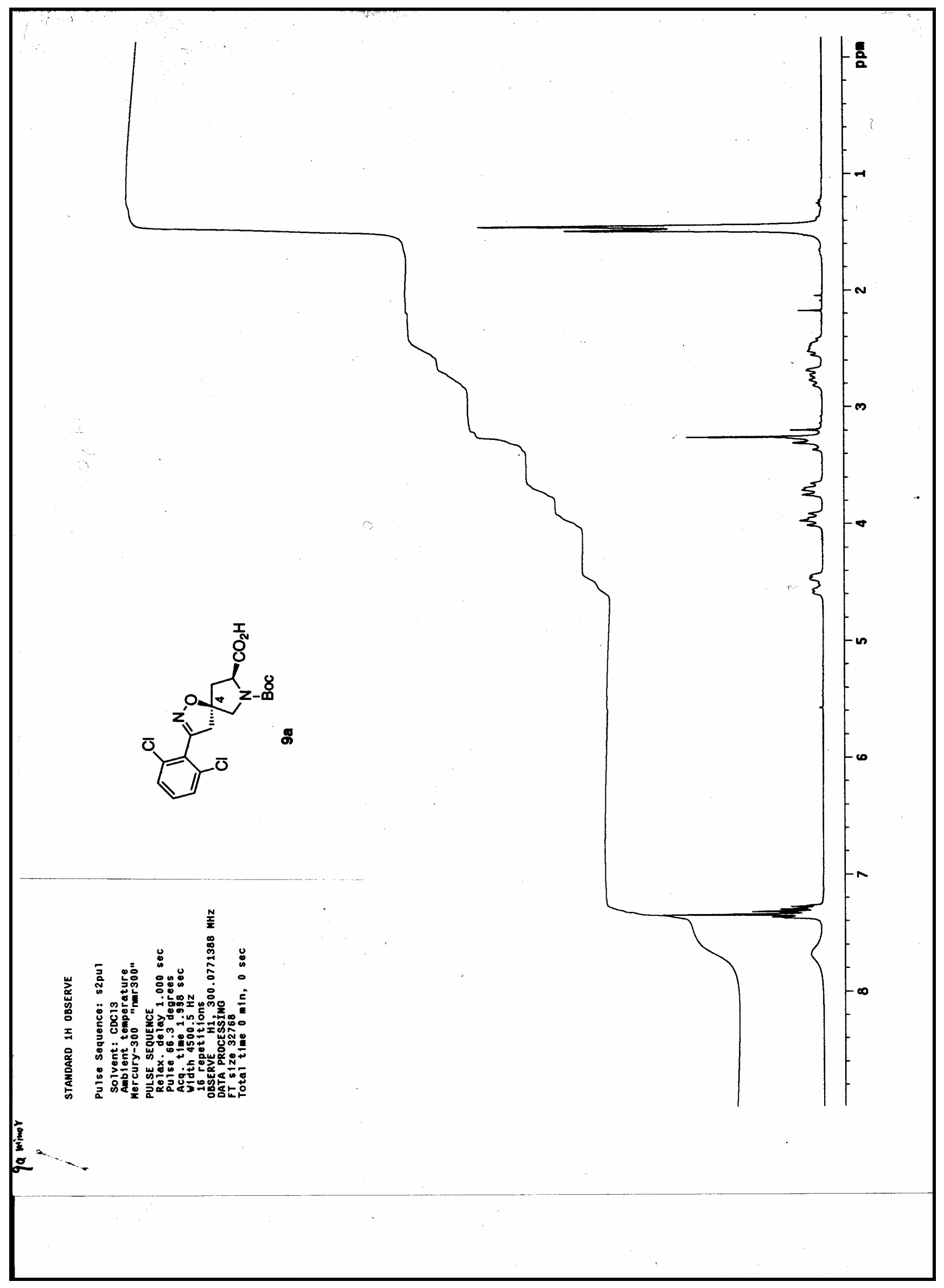




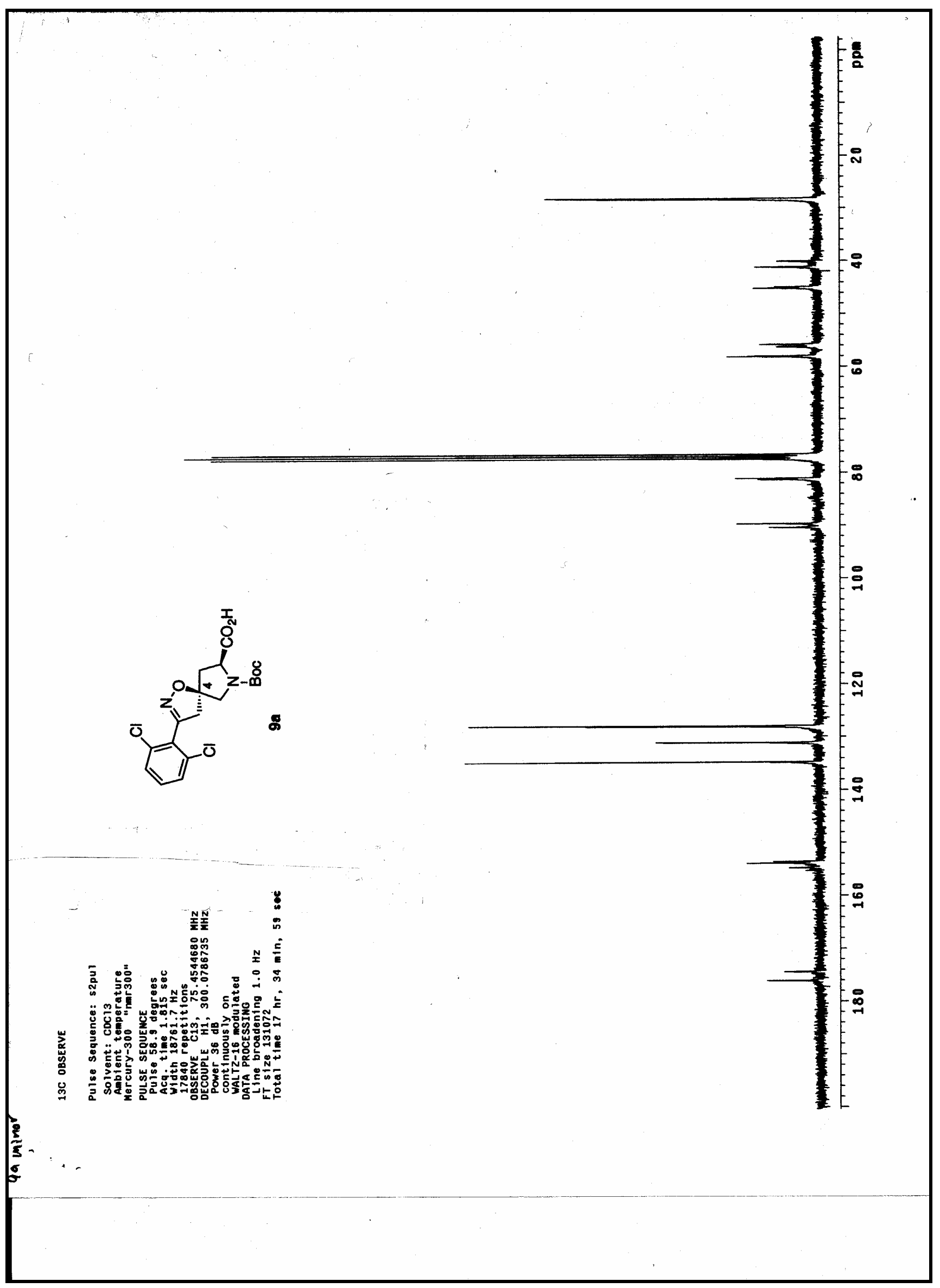




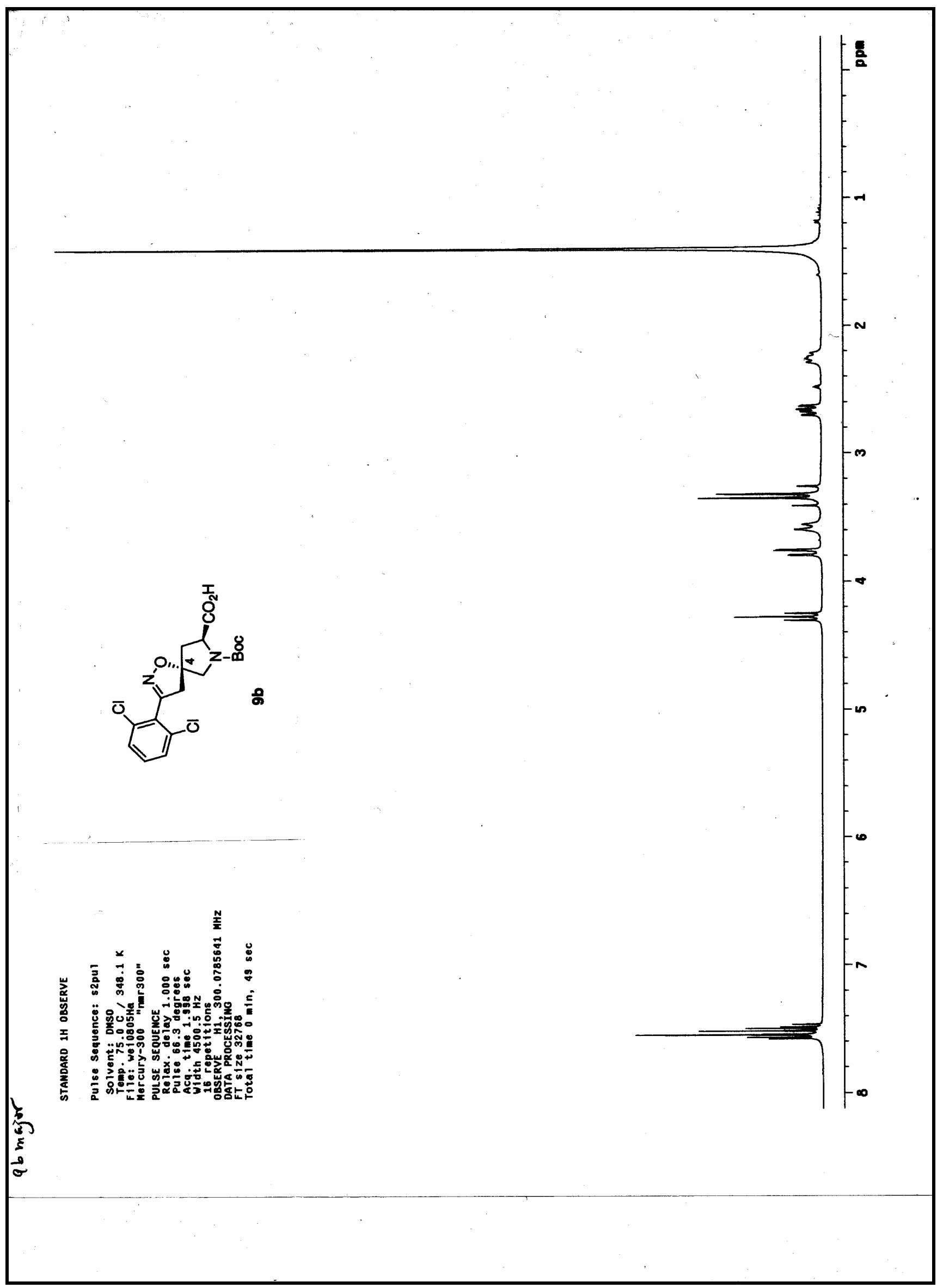




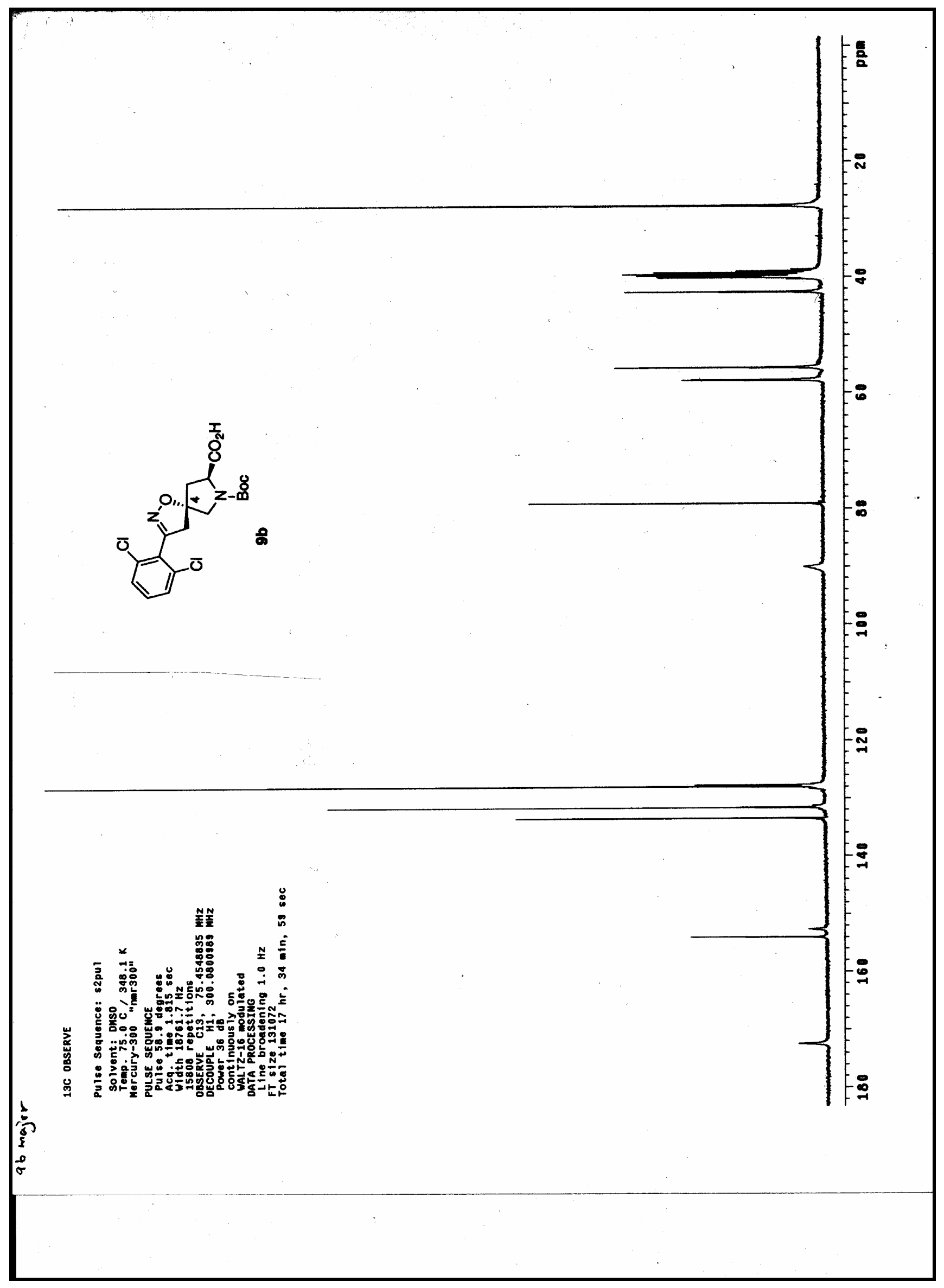


X-ray structure of $9 b$.

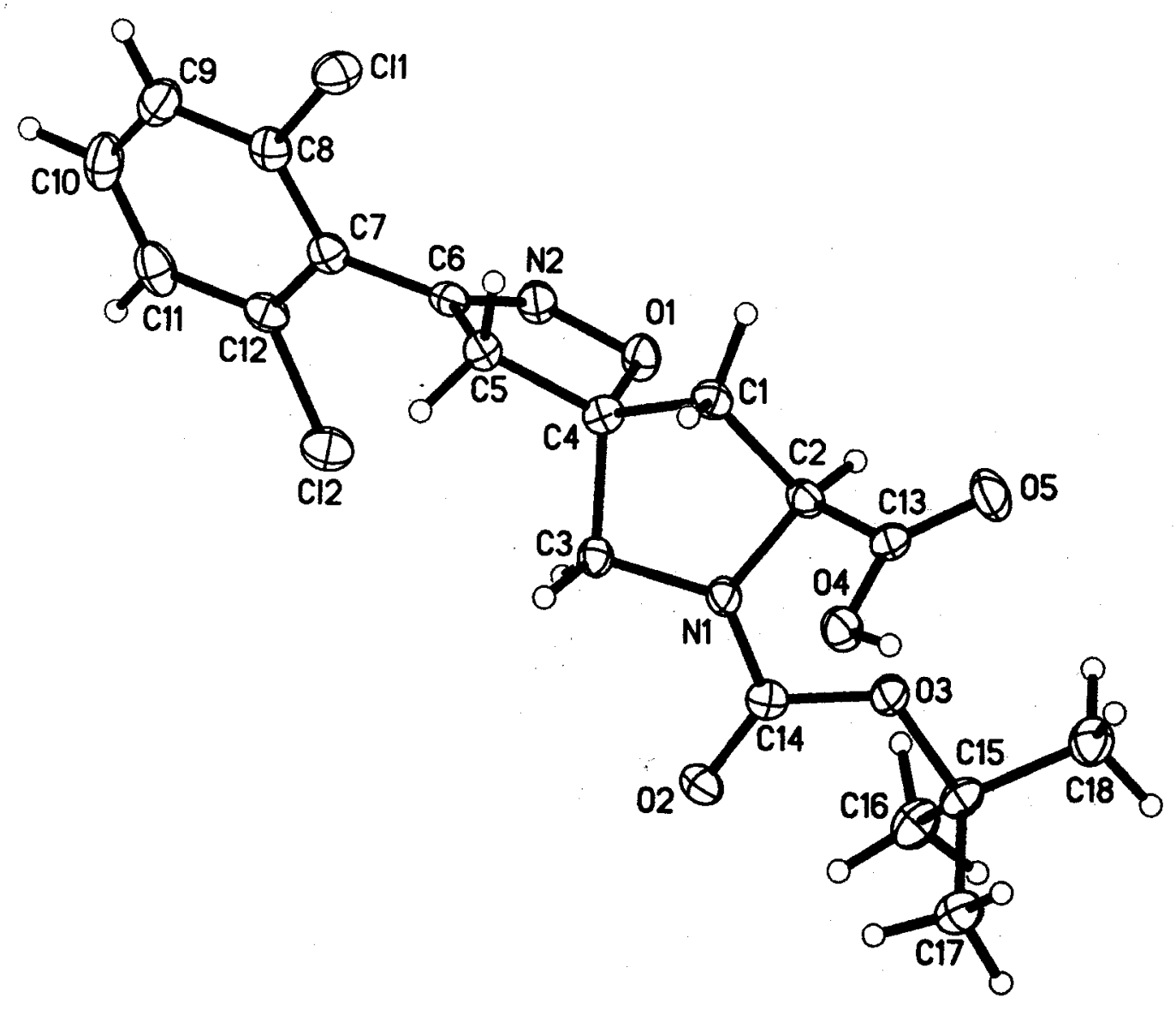




\section{X-ray structure of 13a.}

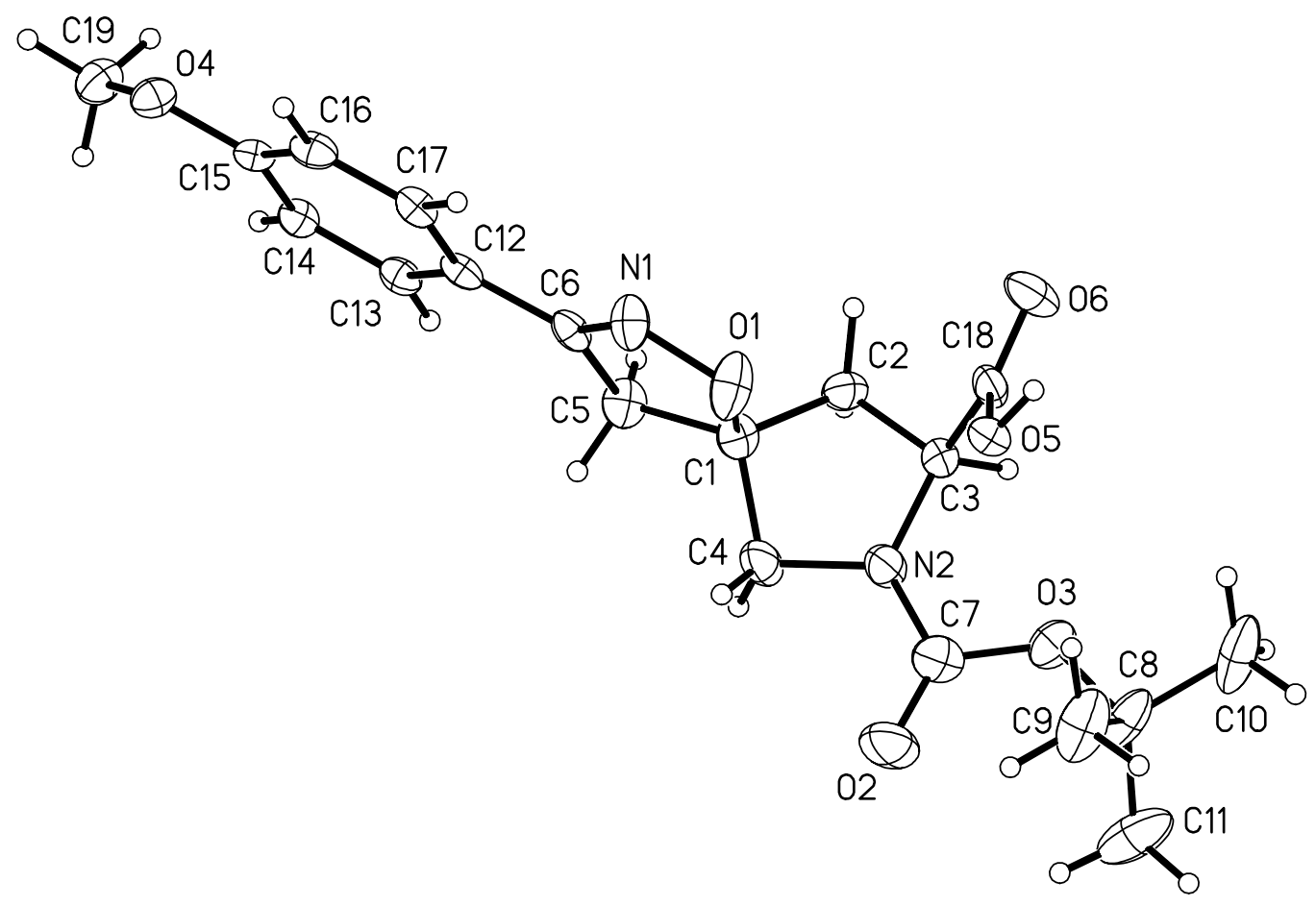


X-ray structure of 15.

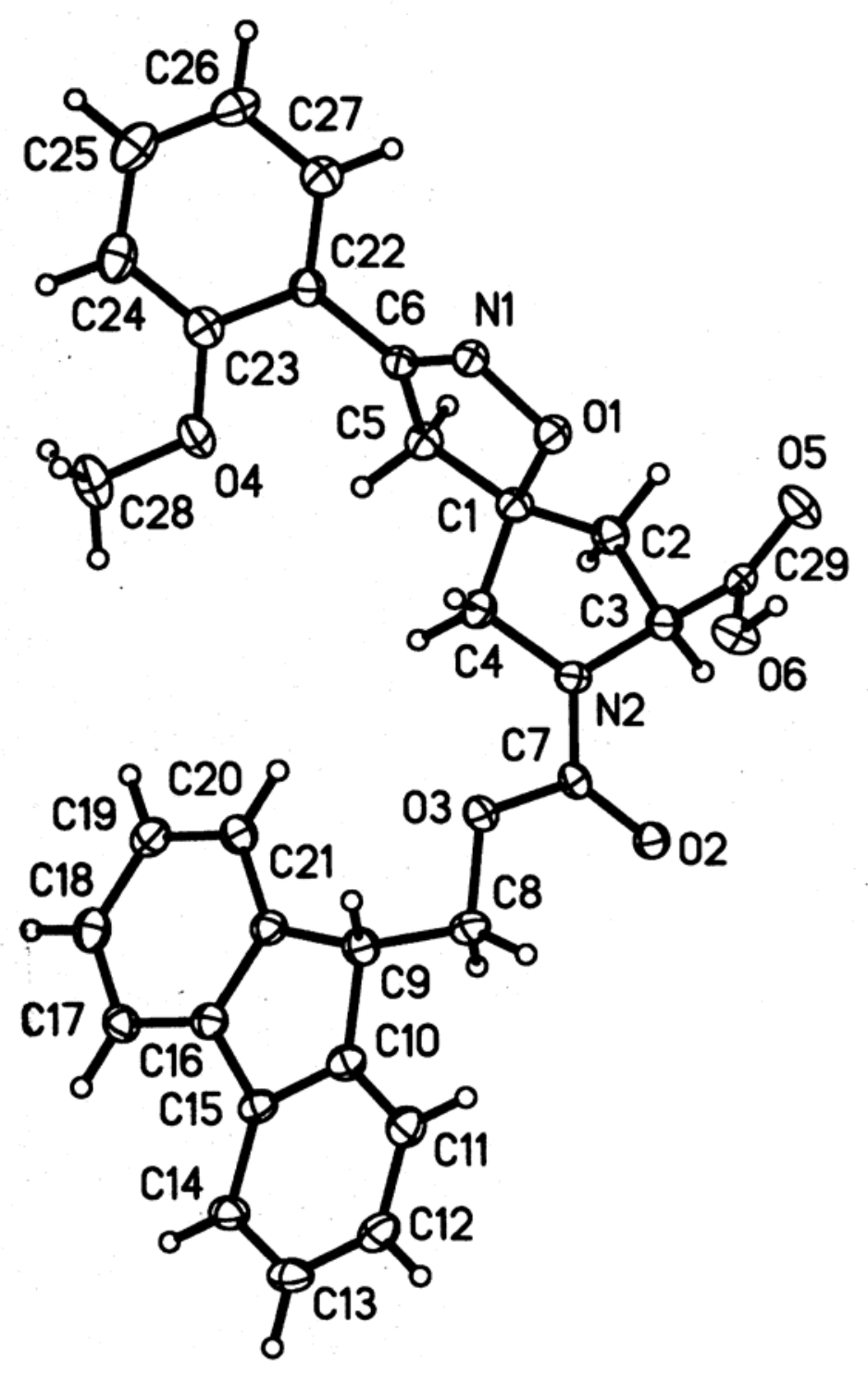

